\title{
Review
}

\section{Prothrombin Complex Concentrates in Post-traumatic Hemorrhage: A Review}

\author{
Ozgur Karcioglu, MD ${ }^{\prime *}$; Ebru Yilmaz, MD²; Selman Yeniocak, MD³; Hakan Topacoglu, MD ${ }^{4}$
}

'Department of Emergency Medicine, University of Health Sciences, Istanbul Education and Research Hospital, Istanbul,Turkey

${ }^{2}$ Department of Emergency Medicine, Nizip Community Hospital, Gaziantep, Turkey

${ }^{3}$ Department of Emergency Medicine, University of Health Sciences, Haseki Education and Research Hospital, Fatih, Istanbul,Turkey

${ }^{4}$ Department of Emergency Medicine, Duzce University, School of Medicine, Duzce,Turkey

\section{*Corresponding author}

Ozgur Karcioglu, MD

Professor, Emergency Physician, Department of Emergency Medicine, University of Health Sciences, Istanbul Education and Research Hospital, PK 34098, Fatih, Istanbul,Turkey;Tel. +90.505.5252399; ORCID ID: 0000-0002-88 |4-6164; E-mail: okarcioglu@gmail.com

\section{Article information}

Received: May $3^{\text {rd }}$, 2019; Revised: August $7^{\text {th }}, 2019$; Accepted: August $27^{\text {th }}, 2019$; Published: August $30^{\text {th }}, 2019$

\section{Cite this article}

Karcioglu O,Yilmaz E, Yeniocak S, Topacoglu H. Prothrombin complex concentrates in post-traumatic hemorrhage:A review. Emerg Med Open J. 2019; 5(I): I-8. doi: $10.17140 / E M O J-5-152$

\section{ABSTRACT |}

Prothrombin complex concentrates (PCC) has long been used to reverse vitamin K antagonists (VKA)-induced coagulopathy rapidly and safely. However, its use in trauma-induced coagulopathy (TIC) in patients not using VKA drugs is yet to be elucidated. This article is a narrative review and analysis of the most recent literature to analyse consequences, and intended effects associated with this treatment modality in TIC. Utilization of PCC was addressed in the literature data found by searches of databases. The indications, efficacy and outcomes associated with the use of the product were reviewed in the articles. Some studies point out promising results with respect to PCC use to overcome the VKA-related coagulopathy in victims of trauma. PCC may be a viable option for resuscitation in emergency and critical care in the management of severe hemodynamic deterioration induced by trauma, despite contradictory findings in the literature.

\section{Keywords}

Blood coagulation factor; Trauma; Hemorrhagic shock; Exsanguinating hemorrhage.

\section{PROTHROMBIN COMPLEX CONCENTRATES FOR TRAUMATIC HEMORRHAGE}

$\mathrm{T}$ rauma is an everlasting challenge to public health worldwide, and hemorrhage is the most common cause of potentially preventable death among victims of trauma. More specifically, one in every two deaths within the first day following injury result from hemorrhage and hemorrhagic shock can lead to post-resuscitation organ failure and related mortality.

Acquired deficiencies related to coagulation cascade are also blamed for the death toll among patients exposed to traumatic injuries. Alterations in prothrombin time (PT) and partial thromboplastin time (PTT) in trauma victims were described first in 2003. ${ }^{2,3}$ These disturbed levels in laboratory correlated with increased mortality and effectively changed the approach to trauma care nowadays.
Contemporary damage control resuscitation encompasses ratio-based transfusion of packed red blood cells, plasma and platelets. Although this approach is still viewed as the "gold standard" of trauma care, goal-directed algorithms directed by coagulation tests or viscoelastic studies may allow a better definition of any given patient's coagulopathy. ${ }^{4}$ This strategy will allow a more individualized and targeted treatment modality. Prothrombin complex concentrate (PCC) are also advocated in many types of coagulopathy, especially those induced by drugs such as vitamin $\mathrm{K}$ antagonist (VKA) and direct oral anticoagulants.

The objective of this research is to highlight the usage characteristics and effects of PCC in trauma-induced coagulopathy (TIC). This article is a review and analysis of the most recent literature to analyse consequences, and intended effects associated with this treatment modality in TIC. 
PROTHROMBIN COMPLEX CONCENTRATES:THE HISTORY AND BACKGROUND

PCC is mostly used to mitigate effects of acute overdose of VKA. Patients with major bleeding while taking VKA-therapy eventually diagnosed with acute overdose of VKA-require rapid reversal of life-threatening coagulopathy. PCC was at first developed to treat hemophilia, the agent is now used for the expedient reversal of untoward high-levels of international normalized ratio (INR). ${ }^{5}$

\section{Structure and Chemıcal Properties}

Two types of PCC are available, the 3-factor and the 4-factor PCC. Literature data support that the 4-factor PCC has greater amounts of factor VII in conjunction with proteins which possess anticoagulant properties (protein- $C$, Antithrombin, and heparin) than the 3-factor PCC. ${ }^{6}$ Four-factor PCC was suggested as the main element of the treatment strategy of VKA-induced bleeding by the current guidelines. ${ }^{7,8}$ Furthermore, there are concrete data from animal and human studies suggesting that 4F-PCC may have similar efficacy in relieving coagulopathy associated with the factor $\mathrm{X}_{\mathrm{a}}$ inhibitors apixaban and rivaroxaban. ${ }^{9,10}$ Likewise, Harrison et al demonstrated that in patients with direct oral anticoagulant and VKA-associated intracranial hemorrhage treated with 4F-PCC had similar outcomes, without any thromboembolic adverse events. ${ }^{11}$

\section{Etiology and Pathophysiology of "Trauma-Induced Coagulopathy" (TIC)}

Tissue damage and hemorrhage during trauma leads to shock, which, in turn, prompts hypoperfusion and systemic endotheliopathy (i.e., inflammation, platelet activation, reduced clotting factor activity, sympathoadrenal activation, and hyperfibrinolysis) (Figure 1).

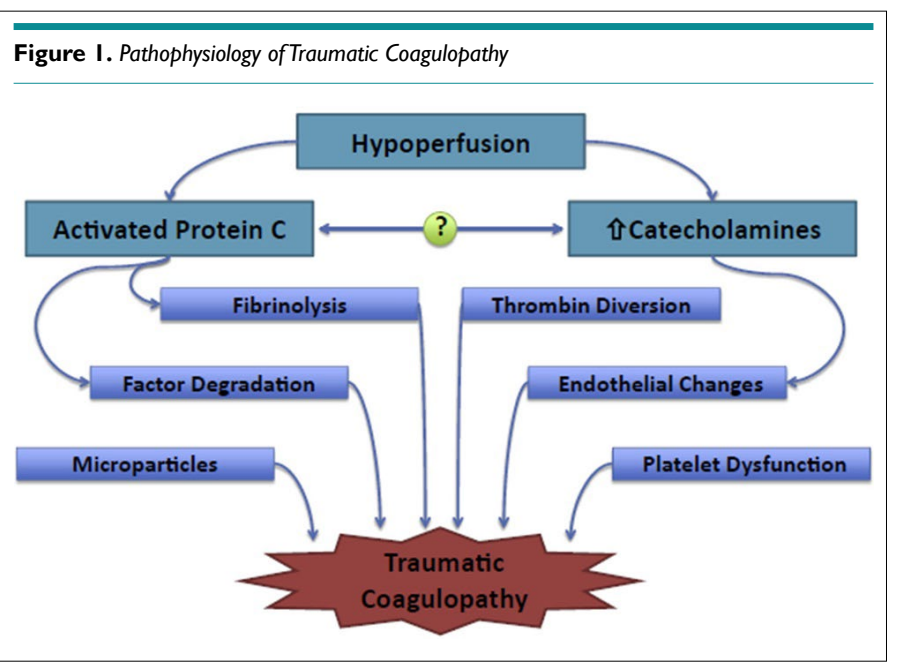

The term "acute traumatic coagulopathy" refers to an endogenous entity, including all components of hemostasis that are triggered by tissue injury, hypoperfusion and shock and pa view the way to coagulation disorder in these patients. ${ }^{4}$ On the other hand, the consequences of shock are also affected by resuscitation-associated factors such as dilution of coagulation factors, hypothermia and acidosis, and also by trauma-associated factors including loss of coagulation factors. ${ }^{12}$ All of these effects culminate to trigger TIC as a multifaceted syndrome threatening many lives at any given time worldwide (Table 1).

Table I. Pathophysiologic Processes Involved in Traumatic Coagulopathy

Endothelialdys function: elevated circulating levels of Syndecan-I (a protein normally found in theglycocaly $x$ of the endothelium)

- Impaired platelet function

Relative thrombocytopenia

Microparticles:Thrombin-richmicroparticles, Circulating endothelial-, Erythrocyte-,Andleukocyte-derived microparticles

Kutcher et al reported a posttraumatic platelet dysfunction accompanied by a normal platelet count and standard clotting studies, with substantial implications for mortality. Multiple electrode impedance aggregometry accurately identified this dysfunctional platelets in trauma cases, and admission arachidonic acid and collagen responsiveness were found to be specific independent predictors of mortality. ${ }^{13}$

One-fourth of critically injured trauma patients are coagulopathic on arrival, increasing to close to $100 \%$ after receiving a massive transfusion. ${ }^{14,15}$ TIC is recognized to be a grave indicator, with greater transfusion need, higher levels of organ dysfunction, and a 4-fold increase in mortality. ${ }^{2,16}$ TIC also leads to poor outcomes with higher transfusion requirements; increased multiorgan system failure, increased hospital, intensive care, and ventilator days; and boosted death toll. . $^{17,18}$

\section{Evaluation of Trauma with Special Emphasis on TIC}

Initial assessment of any trauma victim with bleeding should include exploration of traumatic haemorrhage taking patient's physiology, anatomical injury pattern, mechanism of injury and the patient response to initial resuscitation into account (Grade 1C). ${ }^{12}$ The shock index (SI) can be used as well, to assess the degree of hypovolaemic shock. (Grade 2C). Coagulopathy is encountered in every third of trauma victims. ${ }^{2,3,16}$

Acute blood loss and resultant anemia associated with traumatic hemorrhage can impair the clotting mechanism as well, since anemia may render platelet marginalization more difficult thus slowing platelet activation. ${ }^{12}$ Kutcher et al demonstrated that almost half of patients with serious injuries on presentation and more than $90 \%$ of patients at five days exhibited platelet dysfunction by multiplate impedance aggregometry. ${ }^{13}$ Interestingly, these patients can still have normal platelet counts. They also noted that platelet dysfunction on presentation was predictive of death in patients with multiple trauma.

Coagulopathy in trauma patients can be attributed to the traumatic damage or treatment effect of VKA. Balanced resuscitation is the essential strategy in those with TIC, but optimized ratios for resuscitation and monitoring protocols for transfusion are yet to be elucidated. ${ }^{19}$ In a very recent review, Harris et al cited that the current understanding of TIC is evolving and may see targeted blood component therapy incorporated early in trauma shock 
resuscitation. ${ }^{20}$ In another review, Cohen et al postulated that those with TIC had grave outcomes with transfusion rates, infection, thromboembolism, acute lung injury, organ failure, and mortality. ${ }^{19}$

Coagulopathy is demonstrated to have resulted in a substantially greater fatality rate in those patients with acute injuries. ${ }^{3}$ Recently, the strategy of "damage control resuscitation (DCR)" which encompasses expedient use of blood products with a greater ratio of packed red blood cells to FFP to platelets than the previous regimes is being used. ${ }^{21,22}$ This has been thought to lower the incidence of coagulopathy. ${ }^{22,23}$ Meanwhile, FFP and platelets were claimed to hasten the risks of volume overload and infections attributed to the transfusion of blood product. ${ }^{24,25}$ Likewise, Watson et al demonstrated that the potentials of acute lung injury is the greatest following FFP administration. ${ }^{24}$

Matsushima et al reviewed the literature in 2015 and reported that there are small researches that put forth promising findings with regard to PCC utilization to overcome the VKA-related coagulopathy in trauma victims. ${ }^{26}$ It remains to be answered if PCC can be a remedy in patients in need of massive transfusion.

Uncontrolled hemorrhage including TIC is still among the prominent factors underlying preventable death after trauma, and expedient diagnosis and aggressive management accompany inarguably better outcomes.

Current treatment concepts include the DCR concept, which advocates the empiric administration of blood products in predefined ratios and the concept of 'Goal-directed Coagulation Therapy' (GDCT) based on findings elicited from point-of-care testing.

GDCT based upon viscoelastic testing allows better characterization of the coagulopathy with supplementation of hemostatic agents and blood products according to the individual patient's needs. ${ }^{27}$

\section{HOW MUCH FLUIDTO GIVE?}

At first, a substantial amount of crystalloids is to be administered as a fluid challenge to the victim. Then, the response to this challenge should be criticized in the context of small-volume resuscitation and "permissive hypotension", which is recommended in the trauma patients with hemorrhage. Permissive hypotension with a target systolic pressure of 80 to $90 \mathrm{mmHg}$-in conjunction with a mean arterial pressure of 50 to $60 \mathrm{mmHg}$-till bleeding is halted expediently after trauma without brain injury is a major strategy (Grade 1C). ${ }^{12}$ In other circumstances, a Hb level of 7 to 9 $\mathrm{g} / \mathrm{dL}$ can be targeted (Grade 1C). There is no evidence to support permissive hypotension as the main strategy in pediatric severe trauma. Therefore, permissive hypotension in trauma is not applicable to pediatric cases, which are defined as those under 15 -years of age.

\section{Imaging Studies to Guide Resuscitation}

Focused assessment with sonography in trauma (FAST) ultrasou- nd for the identification of -mostly abdominal- free fluid in patients with trauma. (Grade 1C). Ultrasound should also be viewed as a useful point-of-care guide for fluid deficits or responsiveness.

Multislice computed tomography (MSCT) allows physicians to be capable of timely diagnosis and expedient management of the patient with multiple injuries. Holstein et al pointed out that a $\mathrm{Hb}$ level lower than $8 \mathrm{~g} / \mathrm{dL}$ in patients with pelvic trauma was associated with mortality. ${ }^{28}$

Lactate levels on presentation are an important guide to therapy. The most commonly used cut-off point is $2 \mathrm{mmol} / \mathrm{L}$ and normalization of a high-level in a reasonable time (e.g., 24-hours) is an independent predictor of survival.

\section{Fibrinogen in Trauma}

Currently, it is a well-known fact that a reduction in blood fibrinogen levels are noted in up to two in every five hypotensive trauma victims. ${ }^{29,30}$ Schlimp et al postulated that presentation fibrinogen levels of major trauma patients have strong correlation with rapidly obtainable, routine laboratory parameters such as hemoglobin and base excess. ${ }^{30}$ Therefore, fibrinogen is viewed as a key ingredient of multiple trauma treatment protocols. ${ }^{31}$

\section{Treatment of Posttraumatic Coagulopathy}

Nowadays, the only therapy supported by concrete evidence in patients with TIC is tranexamic acid (TXA) acting as an antifibrinolytic in order to decrease resultant death toll. ${ }^{32-35}$ Furthermore, TXA is usually given empirically because there are suspicion about the accuracy of diagnostic workup to address hyperfibrinolysis in victims of trauma. ${ }^{36}$

CRASH-2 trial (Clinical Randomisation of an Antifibrinolytic in Significant Haemorrhage), pointed out that management of bleeding trauma cases with TXA leads to a more favorable outcome. In combat casualties, empiric use of TXA showed the greatest benefit observed in patients who subsequently required a massive transfusion. ${ }^{33}$

In the treatment of posttraumatic coagulopathy, there are two different modalities recommended which follow:

a. Damage control resuscitation approach, which encompasses the empiric administration of blood products and hemostatic agents in predefined ratios or

b. A targeted approach directed by bedside viscoelastic studies. Current data suggest that a ratio of pRBCs: plasma: platelets of 1:1:1 in massive transfusion may be favorable along with improved outcomes.

\section{DO WE NEED TO INFUSE PCCTO THIS PARTICULAR} PATIENT?

In 2017, Balendran et al researched on a point-of-care prothrom- 
bin time test (POC PT) as a more practical option in detecting those with reduced prothrombin activity. ${ }^{37}$ They concluded that the test represented a fast, simple, and mobile technique to guide PCC or Recombinanthuman prothrombin (MEDI8111) therapy in bleeding victims of trauma. Although the study is now limited to preclinical phase, it can provide the rationale for future clinical validation of the test to support MEDI8111 development and future clinical use in the management of trauma.

\section{Effect of PCC in TIC}

Exsanguination is the most widespread cause of death in trauma. ${ }^{38}$ Replacement of factors is essential in the correction of TIC. For a long time, FFP is being used to mitigate the effects of TIC in the acute setting.

Jehan et al conducted a retrospective analysis of prospectively maintained database of coagulopathic trauma patients to compare 4-PCC+FFP $v$ s. FPP alone for the treatment of TIC. ${ }^{39}$ They reported that FFP is associated with the rapid reversal of INR (373vs. $955 \mathrm{~min} ; p=0.001)$ and reduction in transfusion requirements as compared to FFP alone. The component therapy of 4-PCC also resulted in a reduction in $\mathrm{pRBC}$ units $(7 \mathrm{vs} .9$ units; $p=0.04$ ), and FFP units ( $5 v$. 7 units; $p=0.03$ ) transfused than in those managed only with FFP. 4-PCC as a component therapy along with FFP is superior to FFP alone for the reversal of TIC. PCC is included in the advocated strategy for the acute reversal of VKA-effect in the European guidelines on the management of perioperative and posttraumatic hemorrhage. ${ }^{12}$

Baskaran et al cited that PCC has an off label use in the setting of trauma with massive transfusion. ${ }^{40}$ Some studies have shown better INR reduction with PCC+FFP compared to FFP alone. $^{41}$

It is important to remember that PCC does not contain factor $\mathrm{V}$ and may not be sufficient as a single agent in traumatic causes requiring massive transfusions. ${ }^{40}$ Many prospective clinical researches have linked early TIC to protein-C depletion (activated protein-C elevation), and boosted potential of acute lung injury, ventilator-associated pneumonia, multisystem organ failure, and death. ${ }^{18,42}$

Thromboelastometry (TEM) is useful to guide individualised goal-directed coagulation therapy in patients with traumatic coagulopathy. ${ }^{43,44}$

\section{Head Injury}

The usefulness of PCC has been demonstrated, with evidence of reduced haematoma formation in patients with head injury, ${ }^{45,46}$ and is preferable to FFP for the rapid reversal of the effects of VKAs. ${ }^{47-49}$

\section{ANY DRAWBACKS?}

The propensity of thrombosis-related disorders attributed to infu- sion of PCC should be weighed against the necessity for expedient reversal of coagulopathy. ${ }^{50}$ Of note, thromboembolic events are encountered more frequently in trauma patients with the administration of 3-F PCC than with4-F PCC. ${ }^{51}$

The risk of thrombosis may be more substantial with the use of "activated PCC" (aPCC) as compared to non-activated PCC $^{52}$ due to the presence of activated factor IX, because the PCC infusion precipitates thrombogenicity at the level of factor $\mathrm{X}$ activation as an ingredient of aPCC..$^{53}$

\section{Alternative Agents in the Treatment of TIC}

The routine use of TXA in the posttraumatic hemorrhagic shock was not been sufficiently evidenced for robust recommendations. ${ }^{54}$ Porta et al investigated the efficacy of TXA and PCC on TIC with a severe metabolic acidosis and compare the efficacy of PCC versus FFP to reverse a dilutional coagulopathy. ${ }^{55}$ They noted that TXA and PCC appear to act favorably in correcting TIC in vitro, and TXA had no loss of function in metabolic acidosis.

\section{Safety Issues}

The safety of PCC has been studied by many researchers for the recent decades. Thrombotic events are recognized as the main adverse effects of the treatment and have been postulated to increase in patients treated with higher doses PCC. ${ }^{56}$

\section{Dosing Issues}

PCC formulations used by different brands have a major issue of being non-standardized. Different sources of PCC are standardized based on factor IX levels. The main concern is their compositional differences whose effect on the outcomes are not established clearly. ${ }^{57}$ Some sources of PCC supply a low level of factor VII, which are called 3 F-PCC. These 3 F-PCC are thought to be less efficacious in the treatment of VKAIC..$^{58}$

Khorsand et al performed a systematic review to describe the currently used PCC dosing strategies and to present their efficacy. ${ }^{59}$ They found no evidence that one dosing strategy is superior. Huynh et al. compared PCC doses of $35 \mathrm{IU} / \mathrm{kg}$ with low-dose $(25 \mathrm{IU} / \mathrm{kg}$ ) in correction of their first INR less than 1.5 in adult patients with warfarin-associated traumatic brain injury. ${ }^{60}$ Moderately dosed PCC (35 IU $/ \mathrm{kg}$ ) was associated with a higher percentage of INR reversal, compared to the treatment with a lower dosage of $25 \mathrm{IU} / \mathrm{kg}$ in this group of trauma victims.

Recently, Abdoellakhan et al examined a fixed 1000 IU fIX PCC dosing protocol for ICH, in comparison to a variable dose approach to achieve an INR B 1.5. ${ }^{61}$ The fixed-dose protocol necessitates additional PCC infusions more frequently to achieve the target INR. They concluded that implementation of a fixed dose of 1000 IU fIX cannot be recommended for VKA-related $\mathrm{ICH}$. 


\section{Use in Traumatic Brain Injury and ICH}

Annually almost $1 \%$ of all VKA users develops an intracranial hemorrhage (ICH). ${ }^{6}$ Most guidelines from developed countries recommend administration of 4-F PCC to reverse VKA-therapy in $\mathrm{ICH}$. These recommendations are deprived of consensus on PCC doses or the target INR to be achieved. ${ }^{63}$

Steiner et al assessed the safety and efficacy of FFP versus PCC in patients with VKA-ICH. ${ }^{64}$ In patients with VKA-ICH, 4F PCC can act more favorably than FFP in improving the INR, which appears to be linked with slower enlargement of haematomas. It is also known that the efficacy of PCC on clinical outcomes are yet to be proven, despite the available data are in favor of the utilization of PCC over FFP in intracranial haemorrhage related to VKA. Likewise, PCC provides a much more rapid reversal of coagulopathy than standard treatment with only FFP and vitamin $\mathrm{K}$ in geriatric trauma patients with $\mathrm{ICH} .{ }^{45}$

\section{Comparison of PCC with FFP}

PCC has practical and theoretical advantages to FFP, as it can be used more rapidly and it does not warrant to be thawed or cross-match of blood groups. Goldstein et al compared the efficiency and safety of 4-F PCC with that of FFP in 181 patients with VKAIC who underwent urgent surgical or invasive procedures. ${ }^{48}$ They wrote that 4F-PCC is better than plasma for rapid INR reversal and effective haemostasis in those needing VKA reversal before surgical or invasive procedures (Table 2).

\begin{tabular}{|c|c|c|}
\hline & PCC & FFP \\
\hline Feasibility-ease of use & +++ & + \\
\hline Cost-effectiveness & +++ & + \\
\hline Volume loading & $\begin{array}{l}\text { Loads less } \\
\text { volume }\end{array}$ & $\begin{array}{l}\text { Loads more } \\
\text { volume }\end{array}$ \\
\hline Onset of efficacy & Sooner & Later \\
\hline INR reversal & Morerapid & \\
\hline $\begin{array}{l}\text { Time taken for completion of } \\
\text { treatment }\end{array}$ & Morerapid & \\
\hline $\begin{array}{l}\text { Cardiopulmonary Adverse } \\
\text { effects }\end{array}$ & None & \\
\hline
\end{tabular}

\section{CONCLUSION}

PCC compounds has long been used to reverse coagulopathy following use of VKA. However, its use in TIC in patients not using VKA prescriptions has not been clarified. Some literature data yielded promising results with respect to PCC use to overcome the VKA-related coagulopathy in victims of trauma.

PCC may be a viable option for resuscitation in emergency and critical care in the management of severe hemodynamic deterioration induced by trauma. PCC has practical and theoretical advantages to FFP, as it can be used more rapidly and it does not warrant to be thawed or cross-match of blood groups. TEM can be used to guide individualised therapy in patients with TIC. The indications, efficacy and outcomes associated with the use of PCC in the setting of trauma including scenarios involving pure $\mathrm{ICH}$ and multiple trauma are yet to be thoroughly revised.

\section{CONFLICTS OF INTEREST}

The authors declare that they have no conflicts of interest.

\section{REFERENCES}

1. Kauvar DS, Lefering R, Wade CE. Impact of hemorrhage on trauma outcome: An overview of epidemiology, clinical presentations, and therapeutic considerations. J Trauma. 2006; 60(6): S3S11. doi: 10.1097/01.ta.0000199961.02677.19

2. Brohi K, Singh J, Heron M, Coats T. Acute traumatic coagulopathy. J Trauma. 2003; 54(6): 1127-1130. doi: 10.1097/01. TA.0000069184.82147.06

3. MacLeod JB, Lynn M, McKenney MG, Cohn SM, Murtha M. Early coagulopathy predicts mortality in trauma. J Trauma. 2003; 55(1): 39-44. doi: 10.1097/01.TA.0000075338.21177.EF

4. Caspers M, Maegele M, Fröhlich M. Current strategies for hemostatic control in acute trauma hemorrhage and trauma-induced coagulopathy. Expert Rev Hematol. 2018; 11: 987-995. doi: 10.1080/17474086.2018.1548929

5. Hellstern P, Halbmayer W-M, Köhler M, Seitz R, MüllerBerghaus G. Prothrombin complex concentrates: Indications, contraindications, and risks: A task force summary. Thromb Res. 1999; 95(4): S3-S6. doi: 10.1016/s0049-3848(99)00077-8

6. Grottke O, Levy JH. Prothrombin complex concentrates in trauma and perioperative bleeding. Anesthesiology. 2015; 122(4): 923-931. doi: 10.1097/ALN.0000000000000608

7. Keeling D, Baglin T, Tait C, et al. Guidelines on oral anticoagulation with warfarin - fourth edition. Br J Haematol. 2011; 154: 311 324. doi: 10.1111/j.1365-2141.2011.08753.x

8. Holbrook A, Schulman S,Witt DM, et al. Evidence-based management of anticoagulant therapy: Antithrombotic therapy and prevention of thrombosis, $9^{\text {th }}$ ed: American College of Chest Physicians Evidence-Based Clinical Practice Guidelines. Chest. 2012; 141: e152S-e184S. doi: 10.1378/chest.11-2295

9. Martin AC, Le Bonniec B, Fischer AM, et al. Evaluation of recombinant activated factor VII, prothrombin complex concentrate, and fibrinogen concentrate to reverse apixaban in a rabbit model of bleeding and thrombosis. Int J Cardiol. 2013; 168: 42284233. doi: $10.1016 /$ j.ijcard.2013.07.152

10. Marlu R, Hodaj E, Paris A, Albaladejo P, Crackowski JL, Pernod G. Effect of non-specific reversal agents on anticoagulant 
activity of dabigatran and rivaroxaban: A randomized crossover ex-vivo study in healthy volunteers. Thromb Haemost. 2012; 108: 217-247. doi: 10.1160/TH12-03-0179

11. Harrison SK, Garrett JS, Kohman KN, Kline JA. Comparison of outcomes in patients with intracranial hemorrhage on factor $\mathrm{Xa}$ inhibitors versus vitamin $\mathrm{K}$ antagonists treated with 4-factor prothrombin complex concentrate. Proc (Bayl Univ Med Cent). 2018: 31: 153-156. doi: 10.1080/08998280.2018.1440858

12. Spahn DR, Bouillon B, Cerny V, et al. Management of bleeding and coagulopathy following major trauma: An updated European guideline. Crit Care. 2013; 17(2): R76. doi: 10.1186/cc12685

13. Kutcher ME, Redick BJ, McCreery RC, et al. Characterization of platelet dysfunction after trauma. I Trauma Acute Care Surg. 2012; 73(1): 13-19. doi: 10.1097/TA.0b013e318256deab

14. Floccard B, Rugeri L, Faure A, et al. Early coagulopathy in trauma patients: An on-scene and hospital admission study. Injury. 2012; 43(1): 26-32. doi: 10.1016/j.injury.2010.11.003

15. Brohi K, Cohen MJ, Ganter MT, et al. Acute coagulopathy of trauma: Hypoperfusion induces systemic anticoagulation and hyperfibrinolysis. J Trauma. 2008; 64(5): 1211-1217. doi: 10.1097/ TA.0b013e318169cd3c

16. Maegele M, Lefering R, Yucel N, et al. Early coagulopathy in multiple injury: an analysis from the German Trauma Registry on 8724 patients. Injury. 2007; 38(3): 298-304. doi: 10.1016/j.injury.2006.10.003

17. Cohen MJ, Bir N, Rahn P, et al. Protein C depletion early after trauma increases the risk of ventilator-associated pneumonia. JTrauma. 2009; 67(6): 1176-1181. doi: 10.1097/TA.0b013e3181c1c1bc

18. Cohen MJ, Call M, Nelson M, et al. Critical role of activated protein $\mathrm{C}$ in early coagulopathy and later organ failure, infection and death in trauma patients. Ann Surg. 2012; 255(2): 379-385. doi: 10.1097/SLA.0b013e318235d9e6

19. Cohen MJ, Christie SA. Coagulopathy of trauma. Crit Care Clin. 2017; 33: 101-118. doi: 10.1016/j.ccc.2016.08.003

20. Harris T, Davenport R, Mak M, Brohi K. The evolving science of trauma resuscitation. Emerg Med Clin N Am. 2018; 36: 85-106. doi: 10.1016/j.emc.2017.08.009

21. Rowell SE, Barbosa RR, Diggs BS, et al. Effect of high product ratio massive transfusion on mortality in blunt and penetrating trauma patients. J Trauma. 2011; 71: S353-S357. doi: 10.1097/ TA.0b013e318227ef53

22. Holcomb JB, Zarzabal LA, Michalek JE, et al. Increased platelet: RBC ratios are associated with improved survival after massive transfusion. I Trauma. 2011; 71: S318-S328. doi: 10.1097/ TA.0b013e318227edbb
23. Duchesne JC, McSwain Jr NE, Cotton BA, et al. Damage control resuscitation: The new face of damage control. J Trauma. 2010; 69: 976-990. doi: 10.1097/TA.0b013e3181f2abc9

24. Watson GA, Sperry JL, Rosengart MR, et al. Fresh frozen plas$m$ ma is independently associated with a higher risk of multiple organ failure and acute respiratory distress syndrome. J Trauma. 2009; 67: 221-227. doi: 10.1097/TA.0b013e3181ad5957

25. Inaba K, Branco BC, Rhee P, et al. Impact of the duration of platelet storage in critically ill trauma patients. 2011; 71: 1766-1773. doi: 10.1097/TA.0b013e31823bdbf9

26. Matsushima K, Benjamin E, Demetriades D. Prothrombin complex concentrate in trauma patients. Am J Surg. 2015; 209: $413-$ 417. doi: 10.1016/j.amjsurg.2014.08.019

27. Maegele M, Nardi G, Schochl H. Hemotherapy algorithm for the management of trauma-induced coagulopathy: The German and European perspective. Curr Opin Anesthesiol. 2017; 30: 257-264. doi: $10.1097 /$ ACO.0000000000000433

28. Holstein JH, Culemann U, Pohlemann T, Working Group Mortality in Pelvic Fracture P. What are predictors of mortality in patients with pelvic fractures? Clin Orthop Relat Res. 2012; 470(8): 2090-2097. doi: 10.1007/s11999-012-2276-9

29. Rourke C, Curry N, Khan S, et al. Fibrinogen levels during trauma hemorrhage, response to replacement therapy, and association with patient outcomes. J Thromb Haemost. 2012; 10: 1342-1351. doi: 10.1111/j.1538-7836.2012.04752.x

30. Schlimp CJ, Voelckel W, Inaba K, et al. Estimation of plasma fibrinogen levels based on hemoglobin, base excess and injury severity score upon emergency room admission. Crit Care. 2013; 17(4): R137. doi: 10.1186/cc12816

31. Novak A, Stanworth SJ, Curry N. Do we still need cryoprecipitate? Cryoprecipitate and fibrinogen concentrate as treatments for major hemorrhage - how do they compare? Expert Rev Hematol. 2018; 11: 351-360. doi: 10.1080/17474086.2018.1458610

32. Roberts I, Shakur H, Coats T, et al. The CRASH-2 trial: A randomised controlled trial and economic evaluation of the effects of tranexamic acid on death, vascular occlusive events and transfusion requirement in bleeding trauma patients. Health Technol Assess. 2013; 17(10): 1-79. doi: 10.3310/hta17100

33. Morrison JJ, Dubose JJ, Rasmussen TE, et al. Military application of tranexamic acid in trauma emergency resuscitation (MATTERs) study. Arch Surg. 2012; 147(2): 113-119. doi: 10.1001/archsurg.2011.287

34. Morrison JJ, Dubose JJ, Rasmussen TE, et al. Association of cryoprecipitate and tranexamic acid with improved survival following wartime injury: Findings from the MATTERs II Study. JAMA Surg. 2013; 148(3): 218-225. doi: 10.1001/jamasurg.2013.764 
35. Cole E, Davenport R, Willett K, et al. Tranexamic acid use in severely injured civilian patients and the effects on outcomes: a prospective cohort study. Ann Surg. 2015; 261(2): 390-394. doi: 10.1097/SLA.0000000000000717

36. Rossaint R, Bouillon B, Cerny V, et al. The European guideline on management of major bleeding and coagulopathy following trauma. Crit Care. 2016; 20: 100. doi: 10.1186/s13054-016-1265-x

37. Balendran CA, Henderson N, Olsson M, Lövgren A, Hansson KM. Preclinical evaluation of point-of-care prothrombin time as a biomarker test to guide prothrombin replacement therapy in coagulopathic bleeding. Res Pract Thromb Haemost. 2017; 1(2): 252258. doi: $10.1002 /$ rth2.12027

38. Curry N, Hopewell S, Dorée C, Hyde C, Brohi K, Stanworth $\mathrm{S}$. The acute management of trauma hemorrhage: A systematic review of randomized controlled trials. Crit Care. 2011; 15(2): R92. doi: $10.1186 / \operatorname{cc} 10096$

39. Jehan F, Aziz H, O'Keeffe T, et al. The role of 4-factor prothrombin complex concentrate (4-PCC) in coagulopathy of trauma: A propensity matched analysis. J Trauma Acute Care Surg. 2018; 85(1): 18-24. doi: 10.1097/TA.0000000000001938

40. Baskaran J, Cassagnol M. Prothrombin Complex Concentrate. Florida, USA: Stat Pearls Publishing; 2019.

41. Sellers W, Bendas C, Toy F, et al. Utility of 4-factor prothrombin complex concentrate in trauma and acute-care surgical patients. J Am Osteopath Assoc. 2018; 118(12): 789-797. doi: 10.7556/ jaoa.2018.171

42. Cohen MJ, Kutcher M, Redick B, et al. Clinical and mechanistic drivers of acute traumatic coagulopathy. I Trauma Acute Care Surg. 2013; 75(1 Suppl 1): S40-S47. doi: 10.1097/TA.0b013e31828fa43d

43. Schöchl H, Nienaber U, Maegele M, et al. Transfusion in trauma: thromboelastometry-guided coagulation factor concentratebased therapy versus standard fresh frozen plasma-based therapy. Crit Care. 2011; 15(2): R83. doi: 10.1186/cc10078

44. Ponschab M, Voelckel W, Pavelka M, Schlimp CJ, Schöchl H. Effect of coagulation factor concentrate administration on ROTEM(R) parameters in major trauma. Scand J Trauma Resusc Emerg Med. 2015; 23: 84. doi: 10.1186/s13049-015-0165-4

45. Edavettal M, Rogers A, Rogers F, Horst M, Leng W. Prothrombin complex concentrate accelerates international normalized ratio reversal and diminishes the extension of intracranial hemorrhage in geriatric trauma patients. Am Surg. 2014; 80(4): 372-376.

46. Huttner HB, Schellinger PD, Hartmann M, et al. Hematoma growth and outcome in treated neurocritical care patients with intracerebral hemorrhage related to oral anticoagulant therapy: Comparison of acute treatment strategies using vitamin $\mathrm{K}$, fresh frozen plasma, and prothrombin complex concentrates. Stroke.
2006; 37: 1465-1470. doi: 10.1161/01.STR.0000221786.81354.d6

47. Chai-Adisaksopha C, Hillis C, Siegal DM, et al. Prothrombin complex concentrates versus fresh frozen plasma for warfarin reversal: A systematic review and meta-analysis. Thromb Haemost. 2016; 116(5): 879-890. doi: 10.1160/TH16-04-0266

48. Goldstein JN, Refaai MA, Milling TJ Jr, et al. Four-factor prothrombin complex concentrate versus plasma for rapid vitamin $\mathrm{K}$ antagonist reversal in patients needing urgent surgical or invasive interventions: A phase 3b, open-label, non-inferiority, randomised trial. Lancet. 2015; 385(9982): 2077-2087. doi: 10.1016/S01406736(14)61685-8

49. Sarode R, Milling TJ Jr, Refaai MA, et al. Efficacy and safety of a 4-factor prothrombin complex concentrate in patients on vitamin $\mathrm{K}$ antagonists presenting with major bleeding: A randomized, plasma-controlled, phase IIIb study. Circulation. 2013; 128(11): 1234-1243. doi: 10.1161/CIRCULATIONAHA.113.002283

50. Park MS, Owen BA, Ballinger BA, et al. Quantification of hypercoagulable state after blunt trauma: Microparticle and thrombin generation are increased relative to injury severity, while standard markers are not. Surgery. 2012; 151(6): 831-836. doi: 10.1016/j. surg.2011.12.022

51. Mangram A, Oguntodu OF, Dzandu JK, et al. Is there a difference in efficacy, safety, and cost-effectiveness between 3-factor and 4-factor prothrombin complex concentrates among trauma patients on oral anticoagulants? J Crit Care. 2016; 33: 252-256. doi: 10.1016/j.jcrc.2016.02.018

52. Turpie AG, Kreutz R, Llau J, Norrving B, Haas S. Management consensus guidance for the use of rivaroxaban--an oral, direct factor Xa inhibitor. Thromb Haemost. 2012; 108(5): 876-886. doi: 10.1160/TH12-03-0209

53. Philippou H, Adami A, Lane DA, et al. High purity factor IX and prothrombin complex concentrate (PCC): Pharmacokinetics and evidence that factor IXa is the thrombogenic trigger in PCC. Thromb Haemost. 1996; 76(1): 23-28. doi: 10.1055/s-0038-1650516

54. Napolitano LM, Cohen MJ, Cotton BA, et al. Tranexamic acid in trauma: How should we use it? J Trauma Acute Care Surg. 2013; 74(6): 1575-1586. doi: 10.1097/TA.0b013e318292cc54

55. Porta CR, Nelson D, McVay D, et al. The effects of tranexamic acid and prothrombin complex concentrate on the coagulopathy of trauma: An in vitro analysis of the impact of severe acidosis. J Trauma Acute Care Surg. 2013; 75(6): 954-960. doi: 10.1097/ TA.0b013e31829e20bf

56. Dager WE. Using prothrombin complex concentrates to rapidly reverse oral anticoagulant effects. Ann Pharmacother. 2011; 45: 1016-1020. doi: 10.1345/aph.1Q288

57. Sadeghi N, Kahn D, Cunanan J, et al. Compositional differenc- 
es in commercially available prothrombin complex concentrates. Blood. 2012; 120: 4391.

58. Voils SA, Baird B. Systematic review: 3-factor versus 4-factor prothrombin complex concentrate for warfarin reversal: Does it matter? Thromb Res. 2012; 130: 833-840. doi: 10.1016/j. thromres.2012.10.001

59. Khorsand N, Kooistra HAM, van Hest RM, Veeger NJGM, Meijer K. A systematic review of prothrombin complex concentrate dosing strategies to reverse vitamin $\mathrm{K}$ antagonist therapy. Thromb Res. 2015; 135: 9-19. doi: 10.1016/j.thromres.2014.11.019

60. Huynh TK, Costello JL, Rebuck JA. Optimizing the dose of three-factor prothrombin complex concentrate in traumatic brain injury patients on warfarin therapy. Pharmacotherapy. 2014; 34(3): 260-264. doi: 10.1002/phar.1384

61. Abdoellakhan RA, Miah IP, Khorsand N, Meijer K, Jellema $\mathrm{K}$. Fixed versus variable dosing of prothrombin complex concen- trate in vitamin $\mathrm{K}$ antagonist-related intracranial hemorrhage: A retrospective analysis. Neurocrit Care. 2017; 26: 64-69. doi: 10.1007/ s12028-016-0248-8

62. Schols AM, Schreuder FH, van Raak EP, et al. Incidence of oral anticoagulant-associated intracerebral hemorrhage in the Netherlands. Stroke. 2014; 45: 268-270. doi: 10.1161/ STROKEAHA.113.003003

63. Steiner T, Al-Shahi Salman R, Beer R, et al. European Stroke Organisation (ESO) guidelines for the management of spontaneous intracerebral hemorrhage. Int J Stroke. 2014; 9: 840-855. doi: $10.1111 /$ ijs.12309

64. Steiner T, Poli S, Griebe M, et al. Fresh frozen plasma versus prothrombin complex concentrate in patients with intracranial haemorrhage related to vitamin $\mathrm{K}$ antagonists (INCH): Arandomised trial. Lancet Neurol. 2016; 15: 566-573. doi: 10.1016/ S1474-4422(16)00110-1 